\title{
Electrodeposition of High-Purity Nanostructured Iron Films from Fe(II) and Fe(III) Non-Aqueous Solutions Based on Ethylene Glycol
}

\author{
G. Panzeri ${ }^{\mathrm{a}}$, A. Accogli ${ }^{\mathrm{a}}$, E. Gibertini ${ }^{\mathrm{a}}$, C. Rinaldi ${ }^{\mathrm{b}}$, L. Nobili $^{\mathrm{a}}$, L. Magagnin $^{\mathrm{a}}{ }^{*}$ \\ ${ }^{a}$ Dipartimento di Chimica, Materiali e Ingegneria Chimica Giulio Natta \\ Politecnico di Milano, 20131 Milano, Italy \\ ${ }^{\mathrm{b}}$ Dipartimento di Fisica, Politecnico di Milano, 20133 Milano, Italy \\ * Corresponding author: luca.magagnin@polimi.it
}

Ethylene glycol was studied as solvent for the electrodeposition of iron from both bivalent and trivalent iron chloride solutions. Using cyclic voltammetry $(\mathrm{CV})$ on Pt electrodes, the impossibility to directly reduce $\mathrm{Fe}(\mathrm{III})$ ions to metallic state $\mathrm{Fe}(0)$ was evidenced with the formation of $\mathrm{Fe}$ (II) species was found to be a necessary intermediate step for iron plating. Linear sweep voltammetries (LSVs) were carried out on copper substrate confirming the results previously obtained on platinum. Potentiostatic deposition was performed from both $\mathrm{Fe}(\mathrm{II})$ and $\mathrm{Fe}$ (III) solutions in a broad potential interval (1.5-2.3 V vs $\mathrm{Pt}$ ) to define the threshold value for iron reduction and film formation: the best results were obtained at -1.7 $\mathrm{V}$ vs $\mathrm{Pt}$ for $\mathrm{Fe}(\mathrm{II})$ solution and at $-2.3 \mathrm{~V}$ vs $\mathrm{Pt}$ for $\mathrm{Fe}(\mathrm{III})$ one. Deposits were characterized with field emission scanning electron microscope (FE-SEM) showing a nanostructured morphology with no traces of oxygen in the deposits, resulting in a pure metallic plated iron. X-Ray diffraction patterns showed a preferential orientation of the nanocrystalline deposit along the BCC [110] plane. Iron films showed a good corrosion resistance $\left(\mathrm{E}_{\text {corr }}=-0.54 \mathrm{~V}\right.$ vs $\mathrm{Ag} / \mathrm{AgCl}$ ) in 3.5 wt.\% $\mathrm{NaCl}$ aqueous solution, similar to high purity metallurgical iron sheet $\left(\mathrm{E}_{\mathrm{corr}}=-0.4 \mathrm{~V}\right.$ vs $\left.\mathrm{Ag} / \mathrm{AgCl}\right)$. Vibrating sample magnetometer (VSM) analysis showed a good saturation magnetization $(1500 \pm 100 \mathrm{kA} / \mathrm{m})$ and low coercivity ( 20 Oe) indicative of a high purity iron film. 


\section{Introduction}

Iron and iron-alloys have attracted the interest of many companies and researchers for their physical and magnetic properties. The electrodeposition of iron films is not trivial from aqueous solution due to the oxidation from $\mathrm{Fe}$ (II) to $\mathrm{Fe}(\mathrm{III})$ at the anode or the precipitation of hydroxides $\mathrm{Fe}(\mathrm{OH})_{3}$ at the cathodic surface due to local alkalization. On the other hand, the employment of non-aqueous solutions may be a good alternative, especially for iron-based system, in order to avoid $\mathrm{pH}$ dependence and to obtain high purity deposits [1-6]. Non-aqueous solvents are extensively studied thanks to several advantages with respect to traditional plating baths, i.e. wider electrochemical window, high thermal stability and negligible vapor pressure [7,8]. A great attention is paid to deep eutectic solvents (DES) due to their simple preparation and handling [8-11]. However, such systems normally comprehend a chloride salt (e.g. choline chloride) as hydrogen bond acceptor (HBA) and a hydrogen bond donor (HBD) (e.g. ethylene glycol), typically in 1:2 molar

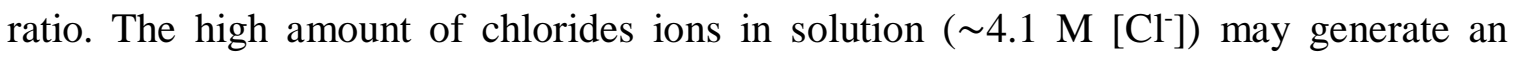
aggressive environment for both the deposit and the substrate. Moreover, choline chloride is highly hygroscopic and its drying represents a critical step for minimizing water intake in the solution. An easy way to have non-aqueous systems is to remove choline chloride using only the HBD as solvent. This approach has been recently studied for a few systems from single metal coating to binary alloys [12-14]. Maltanava et al. [12] carried out a fundamental study on the interaction between ethylene glycol (EG) and Sn(IV) salts showing the formation of stable complexes in the solution [15]. Recently Neuróhr et al. demonstrated the suitability of different alcohols as solvent for the electrodeposition of nickel [13].

In the present work, iron electrodeposition from ethylene glycol solution using both $\mathrm{Fe}(\mathrm{II})$ and $\mathrm{Fe}(\mathrm{III})$ chlorides salts is studied in order to achieve the formation of uniform, compact and high purity magnetic iron film.

\section{Experimental}

Anhydrous Ethylene Glycol $\left[\mathrm{C}_{2} \mathrm{H}_{6} \mathrm{O}_{2}\right]$ (Sigma Aldrich 99.98\%), $\mathrm{FeCl}_{2} \cdot 4 \mathrm{H}_{2} \mathrm{O}$ (Sigma Aldrich 99.99\%) and $\mathrm{FeCl}_{3}$ (Sigma Aldrich 99.99\%) were used as received. 
Ethylene Glycol (EG) was heated up to $70^{\circ} \mathrm{C}$ and subsequently, $0.045 \mathrm{M}$ of iron salts were added obtaining respectively Fe(II) and Fe(III) solutions. The two solutions were kept under stirring until complete dissolution of the metal salts. A conventional three-electrode cell with AMEL2550 Potentiostat/Galvanostat was used for the electrochemical characterization of $\mathrm{Fe}(\mathrm{II})$ and $\mathrm{Fe}(\mathrm{III})$ solutions. Platinum wires were employed as working, counter and pseudo reference electrodes. All Pt electrodes were cleaned in a mixture of nitric acid and hydrochloric acid in 1:3 molar ratio prior each experiment. Linear sweep voltammetry (LSV) and potentiostatic deposition (PD) were carried out on a copper substrate, cleaned with 5\% hydrochloric acid aqueous solution. After deposition, samples were washed thoroughly with water and acetone in order to remove solution traces and dried with $\mathrm{N}_{2}$. Deposits morphology and composition were characterized using Zeiss SUPRA 40 field emission scanning electron microscope (FE-SEM) with in-lens detector and energy dispersive spectroscopy (EDS). The microstructural investigation was carried out by means of X-ray diffraction (XRD) (Philips model PW1830. Ka1 $1_{\mathrm{Cu}}=1.54058 \AA$ ). Potentiodynamic polarization scan $\left(1 \mathrm{mVs}^{-1}\right)$ in $3.5 \mathrm{wt} \% \mathrm{NaCl}$ aqueous solution were performed to assess the corrosion behavior of the films. The magnetic properties were assessed using a vibrating sample magnetometer (VSM, model EZ9 by MicroSense LLC).

\section{Results and discussion}

\subsection{Electrochemical characterization and film deposition}

Solutions containing $0.045 \mathrm{M}$ of iron chlorides salts showed a relatively low conductivity, respectively $0.32 \mathrm{mS} \mathrm{cm}^{-1}$ for $\mathrm{Fe}(\mathrm{II})$ and $0.28 \mathrm{mS} \mathrm{cm}^{-1}$ for $\mathrm{Fe}(\mathrm{III})$ solutions at $25^{\circ} \mathrm{C}$ with no stirring. Eventually, the working temperature selected is $70{ }^{\circ} \mathrm{C}$ increasing the conductivity to $1.09 \mathrm{mS} \mathrm{cm}^{-1}$ for $\mathrm{Fe}(\mathrm{II})$ and $1.07 \mathrm{mS} \mathrm{cm}^{-1}$ for $\mathrm{Fe}(\mathrm{III})$. Cyclic voltammetry was performed at $20 \mathrm{mVs}^{-1}$ scan rate at $70{ }^{\circ} \mathrm{C}$, in $\mathrm{Fe}$ (II) and $\mathrm{Fe}$ (III) solutions with steady and stirred conditions. While for the Fe(II) solution the reduction process expected at the electrode surface can be easily predicted as $\mathrm{Fe}(\mathrm{II}) \rightarrow \mathrm{Fe}(0)$, it is not the same for the $\mathrm{Fe}(\mathrm{III})$ one where the formation of iron divalent species may result in a necessary intermediate step. The lower cathodic limit was set at $-2.5 \mathrm{~V}$ vs Pt; further decreasing of such limit resulted in a porous and black oxide deposit, not allowing a proper stripping during the anodic scan. Considering Fe(II) solution in stagnant conditions, the deposition 
occured at about $-1 \mathrm{~V}$ vs Pt with the formation of a bright deposit on the electrode surface and the cathodic branch formed a broad reduction peak centered at $-1.5 \mathrm{~V}$ vs Pt (Fig. 1). Furthermore, a reduction peak at $+0.05 \mathrm{~V}$ vs $\mathrm{Pt}$ was present, corresponding to the reduction from trivalent iron to bivalent iron ions $[\mathrm{Fe}(\mathrm{III}) \rightarrow \mathrm{Fe}(\mathrm{II})]$ produced during the anodic scan (Figs. 1 and 3). The redox peaks corresponding to $\mathrm{Fe}(\mathrm{II}) / \mathrm{Fe}(\mathrm{III})$ couple were observed in steady conditions where the produced species remained at the working electrode surface, considering the formation of trivalent iron species at $+0.3 \mathrm{~V}$ vs Pt (Fig. 3). Under stirred conditions, for Fe(II) solution the deposition onset was slightly shifted towards more negative potential value from $-1 \mathrm{~V}$ vs Pt to $-1.4 \mathrm{~V}$ vs Pt with an evident change of the slope in the cathodic curve (Fig. 1). During the backward scan, the iron deposit was stripped showing a broader and more intense peak with respect to stagnant conditions, confirming the higher deposition rate occurring during the forward scan. This phenomenon seems to affect strongly the $\mathrm{CV}$ curves obtained for the Fe(III) solution where no direct reduction to metallic state $[\mathrm{Fe}(\mathrm{III}) \rightarrow \mathrm{Fe}(\mathrm{II})]$ occurred at the electrode surface in stirring conditions. Observing the cyclic voltammetries, no stripping peak was observed suggesting that no iron is deposited during the cathodic scan. On the other hands, considering the Fe(III) solution in steady conditions, an iron deposit was formed during the cathodic scan for $\mathrm{V}<$ $-1.5 \mathrm{~V}$ vs Pt and subsequently stripped, showing a broad anodic peak. A possible explanation of this different electrochemical behavior is the need of the intermediate reaction step forming bivalent iron species at the cathode surface subsequently reduced at the metallic state $[\mathrm{Fe}(\mathrm{III}) \rightarrow \mathrm{Fe}(\mathrm{II}) \rightarrow \mathrm{Fe}(0)]$. For the $\mathrm{Fe}(\mathrm{III})$ solution, the reduction to $\mathrm{Fe}(\mathrm{II})$ species occurred at $-0.3 \mathrm{~V}$ vs Pt while corresponding anodic reaction occurs at $+0.05 \mathrm{~V}$ vs Pt. Keeping constant the potential at a suitable value for the reduction [Fe(III) $\rightarrow \mathrm{Fe}(\mathrm{II})]$ to occur, it leaded to a partial or complete conversion of the species in the bath and the solution becomes yellow. 


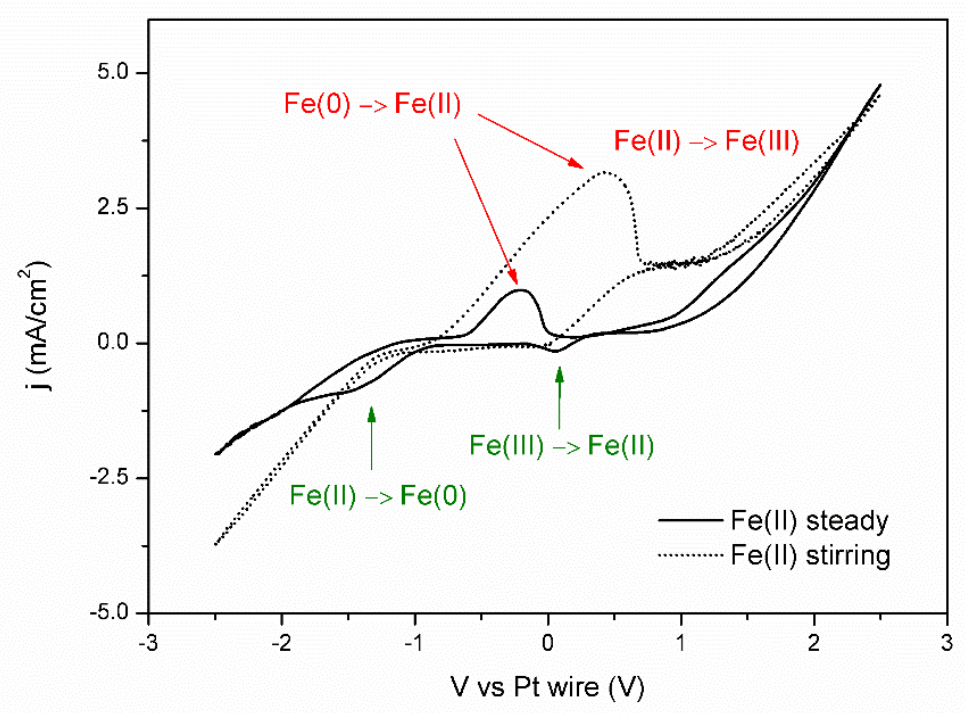

Fig. 1. Cyclic voltammetry of $0.045 \mathrm{M} \mathrm{FeCl}_{2} \cdot 4 \mathrm{H}_{2} \mathrm{O}$ in EG solution under steady and stirred condition $[20 \mathrm{mV}$ $\left.s^{-1}, 70^{\circ} \mathrm{C}\right]$.

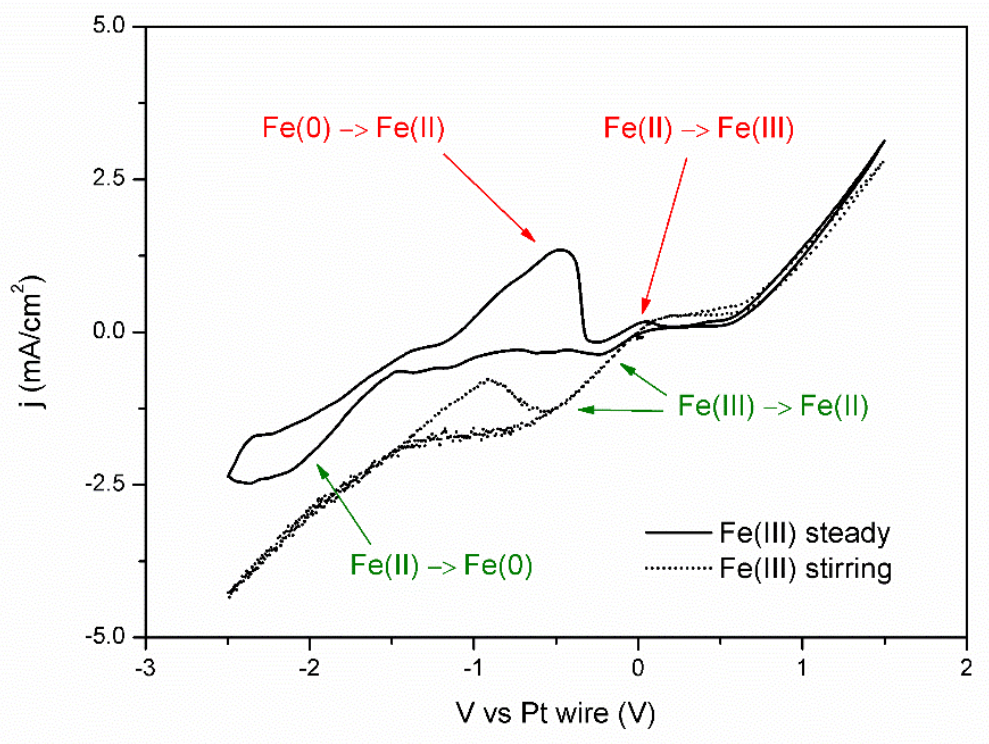

Fig. 2. Cyclic voltammetry of $0.045 \mathrm{M} \mathrm{FeCl}_{3}$ in EG solution under steady and stirred condition $\left[20 \mathrm{mV} \mathrm{s}^{-1}\right.$, $\left.70{ }^{\circ} \mathrm{C}\right]$. 


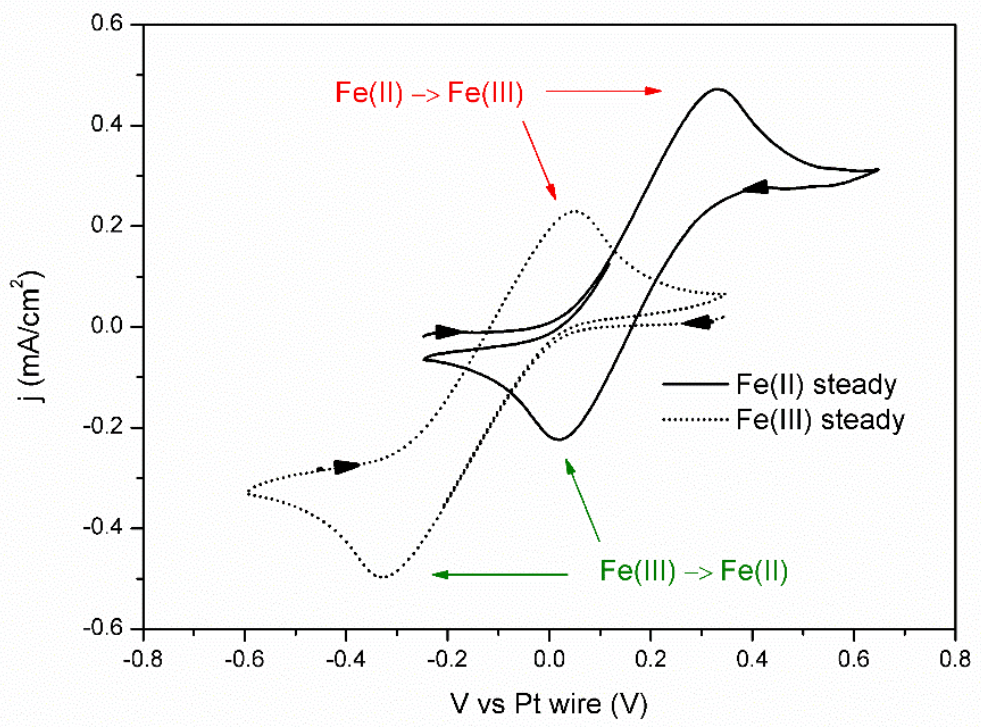

Fig. 3. Cyclic voltammetry of $0.045 \mathrm{M} \mathrm{FeCl}_{2} \cdot 4 \mathrm{H}_{2} \mathrm{O}$ in EG and $0.04 \mathrm{M} \mathrm{FeCl}$ in EG under steady condition [20 $\left.\mathrm{mV} \mathrm{s} \mathrm{s}^{-1}, 70^{\circ} \mathrm{C}\right]$ with reduced potential window.

The deposition process was studied on copper substrates by means of linear sweep voltammetry (LSV) performed at a lower scan rate $\left(5 \mathrm{mVs}^{-1}\right)$ than the cyclic voltammetry. Iron deposition from $\mathrm{Fe}(\mathrm{II})$ solution started at $-1.2 \mathrm{~V}$ vs $\mathrm{Pt}$, corresponding to the increase of the reduction current (Fig. 4). The optimal deposit quality was found at $-1.7 \mathrm{~V}$ vs Pt: no deposition was observed at $-1.3 \mathrm{~V}$ vs Pt while at $-1.5 \mathrm{~V}$ vs Pt the first Fe nuclei started to form. In case of Fe(III) solution under stirred conditions, no deposition occurred up to -8 $\mathrm{V}$ vs Pt while an iron deposit was obtained under steady ones, following the same electrochemical behavior previously shown in the cyclic voltammetry study. Deposits obtained from trivalent iron solution showed a lower quality with oxidized regions and surface defects; moreover, the deposition started at the sample edges proceeding progressively towards the center making to assess the nucleation onset difficult. For this solution, the best result in terms of film formation was found at $-2.3 \mathrm{~V}$ vs Pt. 


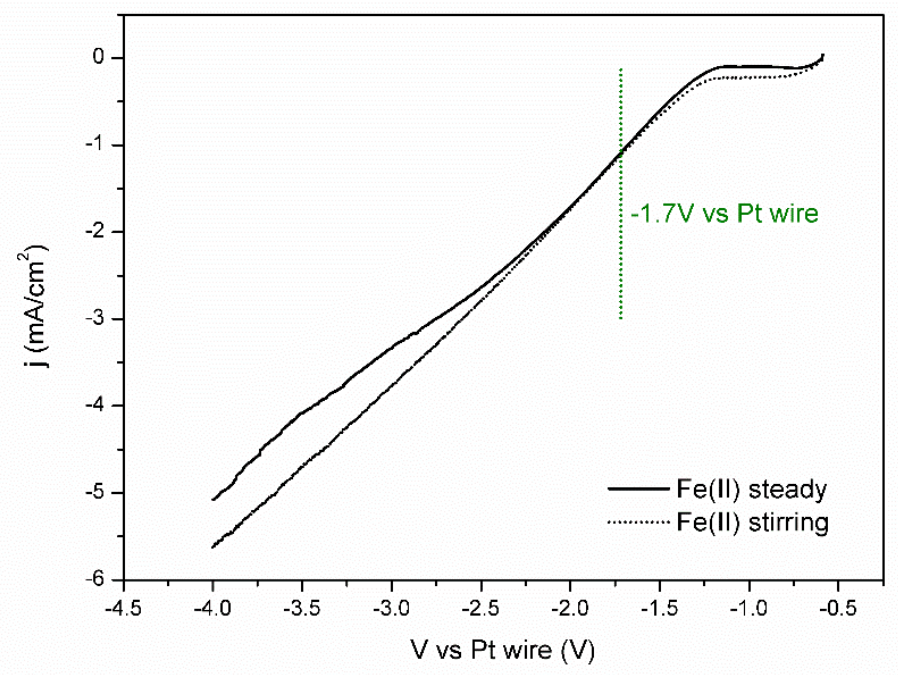

Fig. 4. Linear sweep voltammetry of $0.045 \mathrm{M} \mathrm{FeCl}_{2} \cdot 4 \mathrm{H}_{2} \mathrm{O}$ in EG solution under steady and stirred condition $\left[20 \mathrm{mV} \mathrm{s}^{-1}, 70^{\circ} \mathrm{C}\right]$.

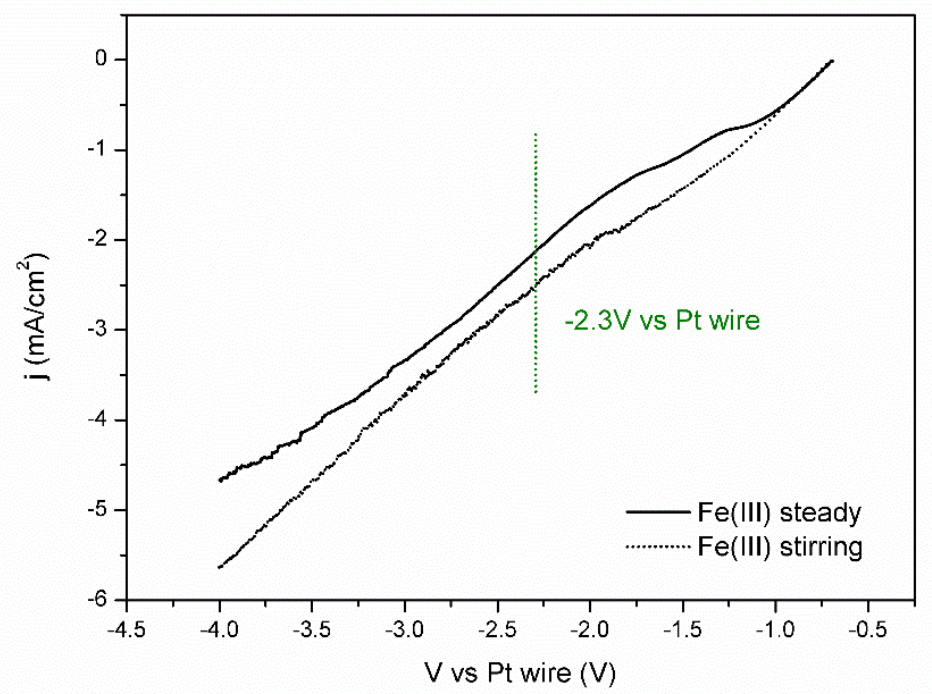

Fig. 5. Linear sweep voltammetry of $0.045 \mathrm{M} \mathrm{FeCl}_{3}$ in EG solution under steady and stirred condition [20 $\left.m V s^{-1}, 70{ }^{\circ} \mathrm{C}\right]$.

\subsection{Film morphology and microstructure}

Field emission scanning electron microscope (FE-SEM) ) was used to characterize the film structure of iron deposits from both Fe(II) and Fe(III) solutions (Figs. 6 and 7 respectively). In general, compact nanostructured films with crystals having characteristic dimensions in the range 50-200 $\mathrm{nm}$. The iron deposits obtained from the Fe(II) solution at 
-1.7 V vs Pt were high-quality ones and energy dispersion spectroscopy (EDS) indicated no traces of oxygen and chlorides. A different morphology resulted for films deposited at $-2.3 \mathrm{~V}$ vs Pt from Fe(III) solution. In this case, the film surface texture was more disordered and characterized by more defects, cracks and discontinuities. Moreover, in contrast with the $\mathrm{Fe}(\mathrm{II})$ solution, $\mathrm{Fe}(\mathrm{III})$ produces films with a relatively high oxygen content (around 10 at.\%), probably due to the difference deposition mechanism involved. Instead, even in the case of $\mathrm{Fe}(\mathrm{III})$ no traces of chlorides were present in the coating, in contrast to some works reporting film contamination employing solutions with high viscosity and concentrated chlorides.
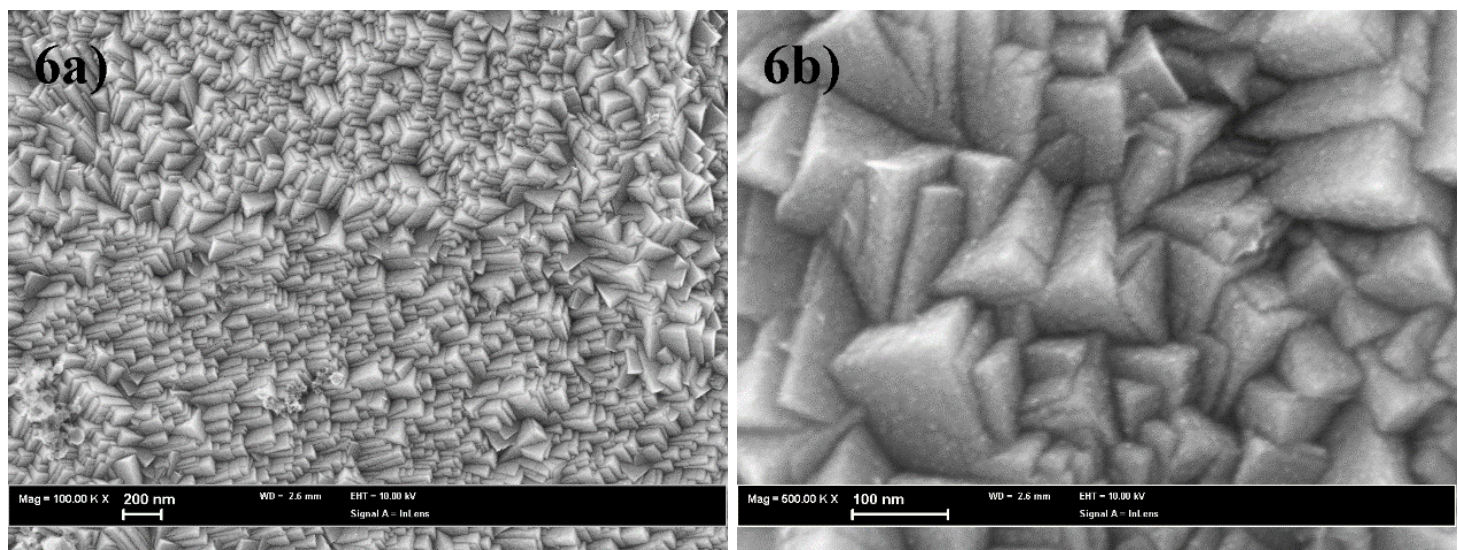

Fig. 6. FE-SEM micrograph of Fe film electrodeposited from EG with $0.045 \mathrm{M} \mathrm{Fe}(\mathrm{II})$ at $-1.7 \mathrm{~V}$ vs $\mathrm{Pt}\left[70^{\circ} \mathrm{C}\right.$, stirring].
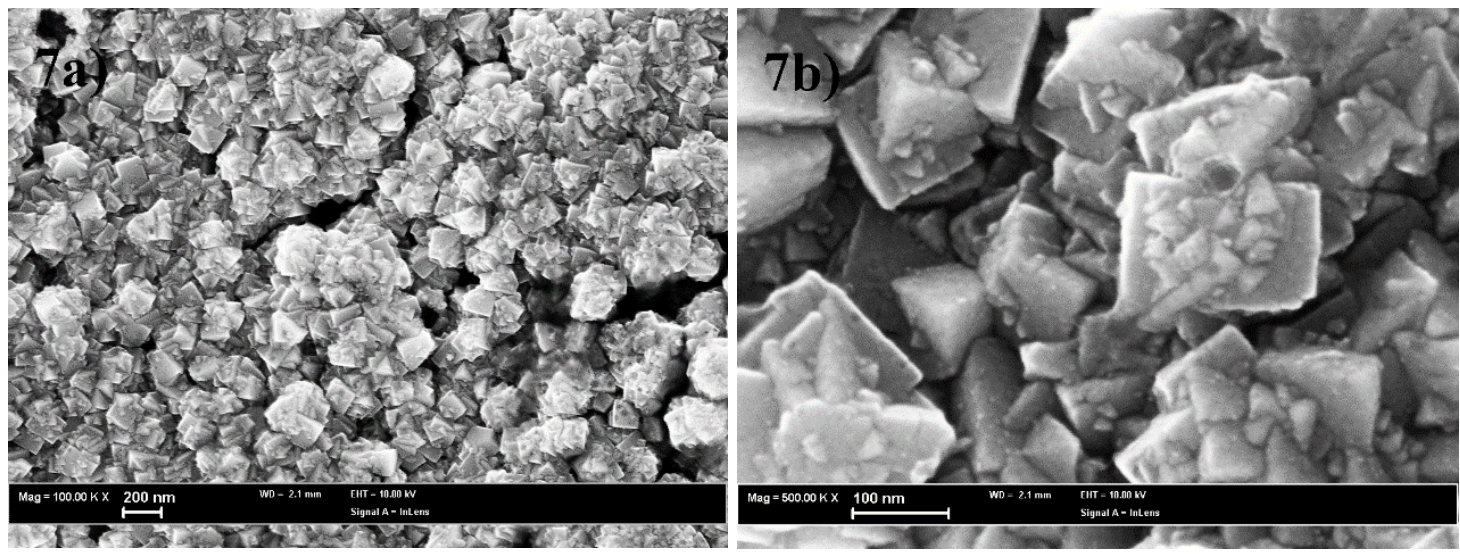

Fig. 7. FE-SEM micrograph of Fe film electrodeposited from EG with $0.045 \mathrm{M} \mathrm{Fe}(\mathrm{III})$ at $-2.3 \mathrm{~V} v \mathrm{Pt}\left[70^{\circ} \mathrm{C}\right.$, steady]. 
X-ray diffraction (XRD) spectra showed similar results for both solutions. In general, the deposits were characterized by a body centered cubic (BCC) microstructure with a preferred (110) out-of-plane orientation. This was particularly true for the deposit obtained at -1.7 V vs Pt from Fe(II) solution where (200) and (211) reflection peaks had respectively $3 \%$ and $9 \%$ intensity of the major reflection peak (110) (Table 1). Using peak deconvolution analysis full width at half maximum (FWHM) was measured for the calculation of the average grain dimension by means of Debey-Sherrer equation. The film resulted to be nanocrystalline with an average grain dimension of $27 \mathrm{~nm}$. Iron deposits from trivalent iron solution showed the same crystal microstructure with a less pronounced preferred orientation.

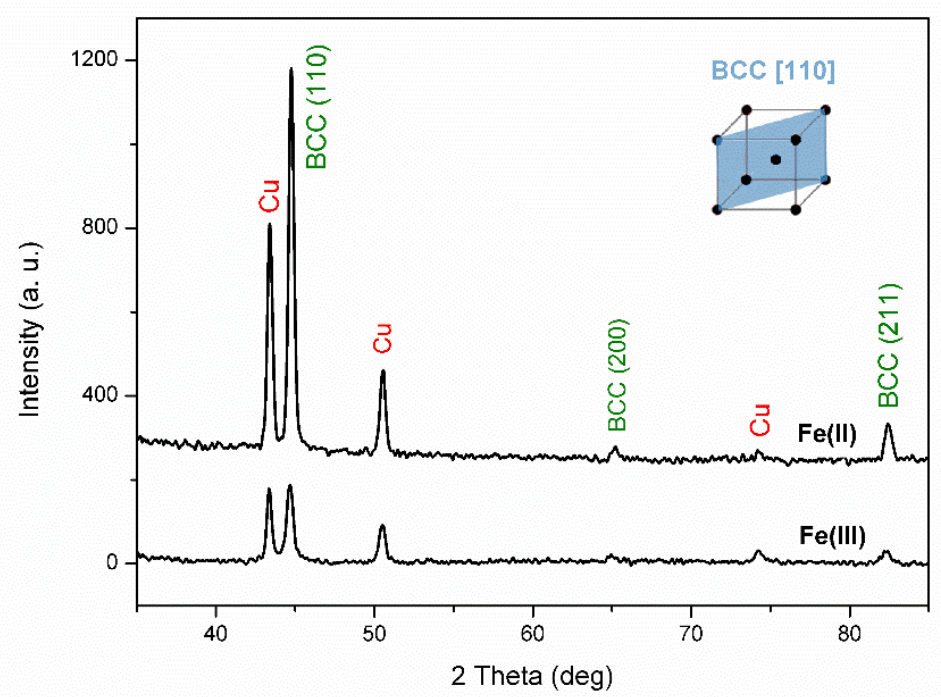

Fig. 8. XRD spectra of Fe films electrodeposited respectively from $\mathrm{Fe}(\mathrm{II})\left[-1.7 \mathrm{~V}\right.$ vs $\mathrm{Pt}$, $70^{\circ} \mathrm{C}$, stirring] and $\mathrm{Fe}(\mathrm{III})\left[-2.3 \mathrm{~V}\right.$ s $\mathrm{Pt}, 70^{\circ} \mathrm{C}$, steady] solutions.

Table 1. Relative intensity of the reflection peaks belonging to different orientation of the body centered cubic (BCC) iron cell. (Reported values belong to the reference JCPDS 06-0696 data and to the electrodeposited films from both divalent and trivalent iron solution.)

\begin{tabular}{llll}
\hline Reflection & JCPDS & Fe(II) film & Fe(III) film \\
\hline BCC (110) & $100 \%$ & $\mathbf{1 0 0 \%}$ & $\mathbf{1 0 0 \%}$ \\
BCC (200) & $20 \%$ & $\mathbf{3 \%}$ & $\mathbf{4 \%}$ \\
BCC (211) & $30 \%$ & $\mathbf{9 \%}$ & $\mathbf{1 4 \%}$ \\
\hline
\end{tabular}




\subsection{Corrosion characterization}

Corrosion potential of iron, in a given environment, is greatly influenced by the amount of impurities in the film (e.g. oxygen) thus the deposits quality is investigated through corrosion test. Iron deposits obtained from Fe(II) solution showed a corrosion potential value relatively close to the reference metallurgical iron sheet (Fe $99.8 \%$ purity) indicating that the obtained film is a pure metallic state with a small amount of impurities. As expected, the iron deposits from Fe(III) solution showed a lower corrosion potential probably due to the oxygen content in the films detected by EDS. The overall corrosion resistance of the films obtained was significantly higher than the ones reported for a trivalent iron DES solution based on urea and choline chloride $\left(\mathrm{E}_{\text {corr }}=-0.935 \mathrm{~V}\right.$ vs $\mathrm{Ag} / \mathrm{AgCl}$ in $0.8 \mathrm{M} \mathrm{NaCl}$ solution at $25^{\circ} \mathrm{C}$ ) [5].

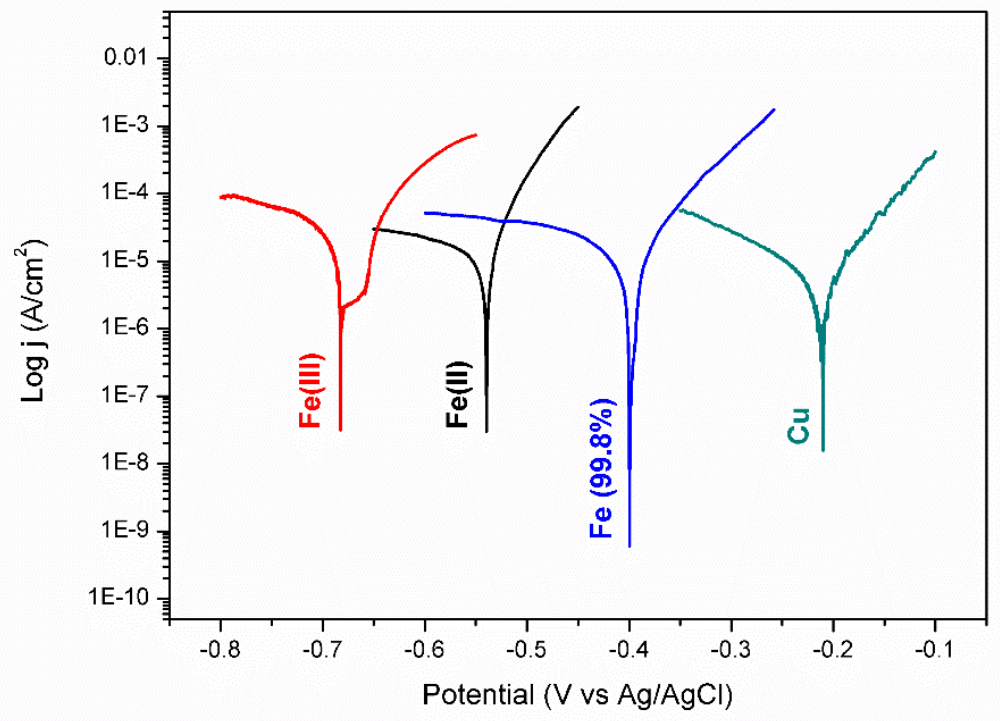

Fig. 9. Potentiodynamic polarization curve of a Fe coating from $\mathrm{Fe}(\mathrm{II})$ and $\mathrm{Fe}(\mathrm{III})$ solutions, reference metallurgical iron $(99.85 \% \mathrm{Fe})$ and $\mathrm{Cu}$ substrate in a $3.5 \mathrm{wt} . \% \mathrm{NaCl}$ aqueous solution at $25^{\circ} \mathrm{C}$.

\subsection{Magnetic characterization}

The magnetic characterization were performed by using a Vibrating Sample Magnetometer (VSM). The hysteresis loop of samples were measured along the in-plane $\left(H_{/ /}\right)$and out-ofplane $\left(H_{\perp}\right)$ directions for the iron films deposited on copper substrates from both bivalent and trivalent solutions. According to diffraction data in Sec. 3.2, these Fe films grows mainly along the (110) direction, with a small percentage of (100) domains. Fe(110) is a 
well-studied system, especially for thin films epitaxially grown on $\mathrm{W}(110)[16,17]$. The out-of-plane direction (110) is known to be a medium-hard axis for Fe because of the magnetocrystalline anisotropy (and shape anisotropy in case of thin films). The easy axis is expected to lay in the film plane and to switch from [110] to [001] when the film thickness is above a critical value $(\sim 10 \mathrm{~nm})$. Note that the thickness of our electroplated films was in the order of some microns and this fades out the role the magnetic shape anisotropy. Moreover, deposits are polycrystalline and textured, so that the isotropic inplane magnetic properties are expected and were verified (data not shown).
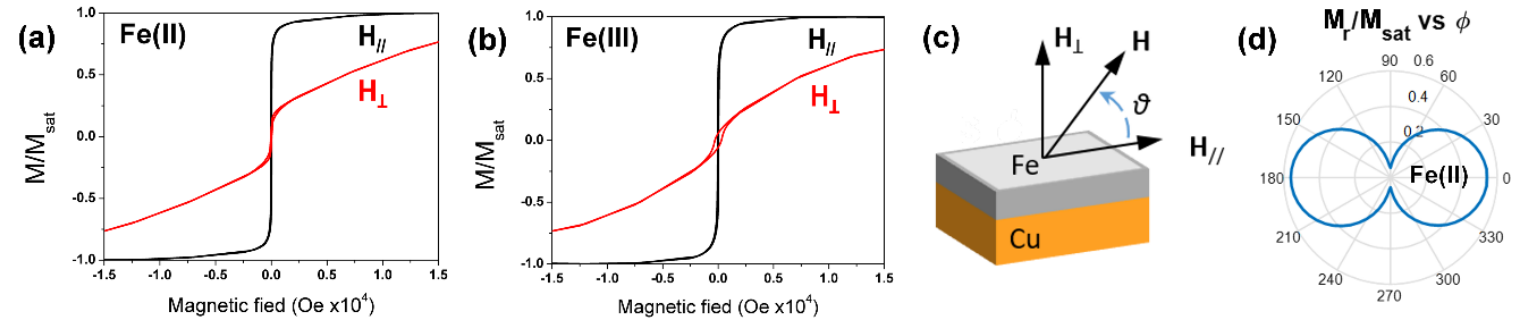

Fig. 10. Hysteresis loops measured on Fe films deposited from $\mathrm{Fe}(\mathrm{II})(\mathrm{a})$ and $\mathrm{Fe}(\mathrm{III})$ solutions (b). (c) Sketch of the magnetic field directions. (d) Squareness of the hysteresis loop versus the angle $\theta$ between the film surface and the applied magnetic field.

Figure 10 reports the in-plane and out-of-plane hysteresis loops for Fe films grown on $\mathrm{Cu}$ by bivalent and trivalent iron solutions. Table 2 summarizes the coercivity and the squareness (the ratio between the remanent magnetization $M_{\mathrm{r}}$ and the saturation magnetization $M_{\text {sat }}$ ) of each loop. In the films plane, both deposits show low coercivity $\left(\sim 20\right.$ Oe), relatively good remanence and squareness $\left(M_{\mathrm{r}} / M_{\mathrm{sat}} \sim 60 \%\right)$.

Both the films are prone to have a hard axis along the out-of-plane direction (s-shaped loops) superimposed to a relatively small hysteresis loop, characterized by a very low remanence magnetization and partially connected to the presence of a certain amount of (100)-oriented Fe crystals. The pronounced in-plane anisotropy of the films was confirmed by measuring the squareness of the hysteresis loop versus the angle $\theta$ between the applied magnetic field and the films surface (Fig. 10c). The result is shown in Fig. 10d for the $\mathrm{Fe}$ (II) case, where the highest (lowest) remanence for the magnetic field parallel (perpendicular) to the film surface confirms the easy axis to be in the films plane.

Moreover, the value of the saturation magnetization achievable at room temperature was found to be $M_{\mathrm{s}}=1500 \pm 100 \mathrm{kA} / \mathrm{m}$ for a $\mathrm{Fe}(\mathrm{II})$ film grown on a brass substrate, reasonably close to the value of $1742 \mathrm{kA} / \mathrm{m}$ expected for an ideal single crystal Fe at zero temperature. 
Note that the uncertainty comes from the determination of the magnetic volume and the absolute value of $M \mathrm{~s}$ is potentially reduced by the partial oxidation of iron at the uncapped surface, exposed to atmosphere before magnetic measurements.

We conclude that electroplating of iron from bivalent and trivalent ethylene glycol based solutions results in soft magnetic films with relatively good magnetic behavior.

Table 2. Values of coercive field and loop squareness from the hysteresis loops measured in the in-plane and out-of-plane direction on $\mathrm{Fe} / \mathrm{Cu}$ grown with bivalent and trivalent iron solutions.

\begin{tabular}{llcc}
\hline Solution & Direction & $\boldsymbol{H}_{\mathbf{C}}[\mathbf{O e}]$ & Squareness $\left(\mathbf{M}_{\mathbf{r}} / \mathbf{M}_{\mathbf{s a t}}\right)[\%]$ \\
\hline $\mathrm{Fe}(\mathrm{II})$ & In-plane $\left(H_{/ /}\right)$ & 23 & $62 \pm 3 \%$ \\
$\mathrm{Fe}(\mathrm{II})$ & Out-of-plane $\left(H_{\perp}\right)$ & 38 & $8 \pm 1 \%$ \\
$\mathrm{Fe}(\mathrm{III})$ & In-plane $\left(H_{/ /}\right)$ & 31 & $54 \pm 1 \%$ \\
$\mathrm{Fe}(\mathrm{III})$ & Out-of-plane $\left(H_{\perp}\right)$ & 290 & $5 \pm 1 \%$ \\
\hline
\end{tabular}

\section{Conclusions}

In this study, we propose a simple and effective solution for the electrodeposition of highpurity iron films based on both divalent and trivalent cations. Cyclic voltammetry results showed the reduction from $\mathrm{Fe}(\mathrm{II})$ to metallic state $\mathrm{Fe}(0)$, even for the $\mathrm{Fe}(\mathrm{III})$ solution suggesting the presence of an intermediate reaction step to Fe(II). Scanning electron microscope (SEM) and electron dispersive spectroscopy (EDS) analysis showed a high purity nanostructured iron films at $-1.7 \mathrm{~V}$ vs Pt from the Fe(II) solution. Lower quality deposits were obtained from Fe(III) solution but with similar nanostructured features. Deposits microstructure were analyzed by mean of X-Rays diffraction (XRD) showing a BCC structure with a preferred orientation along (110), through Debey-Sherrer approach the average gran size of $27 \mathrm{~nm}$ was obtained. Polarization test in $3.5 \mathrm{wt} \% \mathrm{NaCl}$ aqueous solution showed that iron films $\left(\mathrm{E}_{\mathrm{corr}}=-0.54 \mathrm{~V}\right.$ vs $\left.\mathrm{Ag} / \mathrm{AgCl}\right)$ obtained are similar in purity to the metallurgical iron sheet (Fe 99.8\%). The deposition results in good soft magnetic films with low coercivity ( 20 Oe) and in-plane anisotropy.

\section{Acknowledgments}

C. Rinaldi is grateful to Marco Monticelli for helpful discussion. 


\section{References}

[1] SM Gengan Saravanan. Electrodeposition of Fe-Ni-Cr alloy from Deep Eutectic System containing Choline chloride and Ethylene Glycol, Int.J.Electrochem.Sci. 6 (2011) 1468-1478.

[2] R Maizi, P Fricoteaux, A Mohamadou, A Meddour, C Rousse. Electrodeposition of Ni, $\mathrm{Fe}$ and Ni-Fe Alloys in Two Ionic Liquids:(tri (n-butyl)[2-methoxy-2-oxoethyl] Ammonium bis (trifluoromethylsulfonyl)[BuGBOEt][Tf2N] and (1-butyl-1methylpyrrolidinium bis trifluoromethylsulfonyl) imide ([P1, 4][Tf2N]), INTERNATIONAL JOURNAL OF ELECTROCHEMICAL SCIENCE. 11 (2016) 71117124.

[3] T Yanai, K Shiraishi, Y Watanabe, M Nakano, T Ohgai, K Suzuki, et al. Electroplated Fe-Ni Films Prepared From Deep Eutectic Solvents, IEEE Trans.Magn. 50 (2014) 1-4.

[4] T Yanai, K Shiraishi, T Akiyoshi, K Azuma, Y Watanabe, T Ohgai, et al. Electroplated Fe-Co-Ni films prepared from deep-eutectic-solvent-based plating baths, AIP Advances. 6 (2016) 055917.

[5] R Böck, S Wulf. Electrodeposition of iron films from an ionic liquid ( $\mathrm{ChCl} / \mathrm{urea} / \mathrm{FeCl} 3$ deep eutectic mixtures), Transactions of the IMF. 87 (2009) 28-32.

[6] MA Miller, JS Wainright, RF Savinell. Iron Electrodeposition in a Deep Eutectic Solvent for Flow Batteries, J.Electrochem.Soc. 164 (2017) A796-A803.

[7] T Welton. Room-temperature ionic liquids. Solvents for synthesis and catalysis, Chem.Rev. 99 (1999) 2071-2084.

[8] AP Abbott, KJ McKenzie. Application of ionic liquids to the electrodeposition of metals, Physical Chemistry Chemical Physics. 8 (2006) 4265-4279.

[9] EL Smith, AP Abbott, KS Ryder. Deep eutectic solvents (DESs) and their applications, Chem.Rev. 114 (2014) 11060-11082.

[10] AP Abbott, D Boothby, G Capper, DL Davies, RK Rasheed. Deep eutectic solvents formed between choline chloride and carboxylic acids: versatile alternatives to ionic liquids, J.Am.Chem.Soc. 126 (2004) 9142-9147.

[11] R Bernasconi, G Panzeri, A Accogli, F Liberale, L Nobili, L Magagnin, Electrodeposition from Deep Eutectic Solvents, Progress and Developments in Ionic Liquids, InTech, 2017,.

[12] H Maltanava, T Vorobyova, O Vrublevskaya. Electrodeposition of tin coatings from ethylene glycol and propylene glycol electrolytes, Surface and Coatings Technology. 254 (2014) 388-397. 
[13] K Neuróhr, L Pogány, B Tóth, Á Révész, I Bakonyi, L Péter. Electrodeposition of Ni from various non-aqueous media: the case of alcoholic solutions, J.Electrochem.Soc. 162 (2015) D256-D264.

[14] T Vorobyova, O Vrublevskaya. Electrochemical deposition of gold-tin alloy from ethylene glycol electrolyte, Surface and Coatings Technology. 204 (2010) 1314-1318.

[15] D Knetsch, W Groeneveld. Alcohols as ligands: part IV. Complexes of ethylene glycol with some metal (II) sulfates and nitrates, Recueil des Travaux Chimiques des Pays-Bas. 92 (1973) 855-864.

[16] H Elmers, U Gradmann. Magnetic anisotropies in Fe (110) films on W (110), Appl.Phys.A. 51 (1990) 255-263.

[17] U Gradmann, J Korecki, G Waller. In-plane magnetic surface anisotropies in Fe (110), Applied Physics A. 39 (1986) 101-108. 